$$
\text { CONF-970135-6 }
$$

\title{
Some Preliminary Results
from the NWTC Direct-D
Variable-Speed Test Bed \\ Some Preliminary Results
from the NWTC Direct-Drive,
Variable-Speed Test Bed \\ Some Preliminary Results
from the NWTC Direct-D
Variable-Speed Test Bed
}

RECEIVED Nov 201996

O \&TI

Palmer W. Carlin

Lee Jay Fingersh

Prepared for

1997 ASME Wind Energy Symposium

Reno, Nevada

January 6-9, 1997

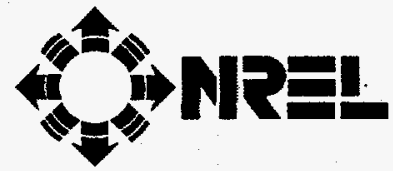

National Renewable Energy Laboratory 1617 Cole Boulevard

Golden, Colorado 80401-3393

A national laboratory of the U.S. Department of Energy Managed by Midwest Research Institute for the U.S. Department of Energy under contract No. DE-AC36-83CH10093

Prepared under Task No. WE618330

October 1996 


\section{NOTICE}

This report was prepared as an account of work sponsored by an agency of the United States government. Neither the United States government nor any agency thereof, nor any of their employees, makes any warranty, express or implied, or assumes any legal liability or responsibility for the accuracy, completeness, or usefulness of any information, apparatus, product, or process disclosed, or represents that its use would not infringe privately owned rights. Reference herein to any specific commercial product, process, or service by trade name, trademark, manufacturer, or otherwise does not necessarily constitute or imply its endorsement, recommendation, or favoring by the United States govemment or any agency thereof. The views and opinions of authors expressed herein do not necessarily state or reflect those of the United States government or any agency thereof.

Available to DOE and DOE contractors from:

Office of Scientific and Technical Information (OSTI)

P.O. Box 62

Oak Ridge, TN 37831

Prices available by calling (423) $576-8401$

Available to the public from:

National Technical Information Service (NTIS)

U.S. Department of Commerce

5285 Port Royal Road

Springfield, VA 22161

(703) $487-4650$ 


\section{DISCLAIMER}

Portions of this document may be illegible in electronic image products. Images are produced from the best available original document. 


\title{
SOME PRELIMINARY RESULTS \\ FROM THE \\ NWTC DIRECT-DRIVE, VARIABLE-SPEED TEST BED ${ }^{1}$
}

\author{
Palmer W. Carlin, Senior Electrical Engineer \\ and \\ Lee Jay Fingersh, Research Associate \\ National Renewable Energy Laboratory \\ Golden, Colorado 80401
}

\begin{abstract}
With the remarkable rise in interest in variable-speed operation of larger wind turbines, it has become important for the National Wind Technology Center (NWTC) to have access to a variable-speed test bed that can be specially instrumented for research. Accordingly, a threebladed, 10-meter, downwind, Grumman Windstream machine has been equipped with a set of composite blades and a direct-coupled, permanent-magnet, 20 kilowatt generator. This machine and its associated control system and data collection system are discussed. Several variations of a maximum power control algorithm have been installed on the control computer. To provide a baseline for comparison, several constant speed algorithms have also been installed. The present major effort is devoted to daytime, semi-autonomous data collection.
\end{abstract}

\section{Initial Purpose of The Tests}

Although the final evaluation of a variable-speed wind system must include the entire power train including any power electronics, a more complete insight into the system will be secured if the individual elements of the train are well understood. Therefore the first NWTC experimental goal was to obtain test data to allow comparison of the total long term energy collected at the hub of a variable speed machine with the total energy collected by an otherwise equivalent constant speed machine.

Visualization of the ideal phase plane paths of these two systems can be aided through the use of a power surface.
A computer simulation of such a surface is shown in Figures 1 and 2, where Figure 2 is a contour plot of the three-dimensional surface in Figure 1. This contour presentation is useful for mapping the operating locus of the wind machine on this surface because constant tipspeed ratio loci appear as straight lines with slopes equal to the tip speed ratio.

\section{Test Bed Description}

To provide the required variable-speed test bed on short notice, the NWTC elected to combine the following components.

The Grumman Windstream 33 - This wind machine is one of two at the NWTC. The sister to this machine has been in service as the Combined Experiment Test Bed for several years. The 25 kilowatt ( $\mathrm{kW}$ ) Windstream 33 is athree-bladed, downwind machine with pitchable blades in a rigid hub. The blade pitch is driven by a reversible induction motor either toward stall or toward feather. The original factory-supplied aluminum rotor was 10 meters ( 33 feet) in diameter.

Blades - For the Unsteady Aerodynamics Combined Experiment Test mentioned above, the original Grummansupplied blades were replaced with SERI S809 blades. These blades, which are members of the Solar Energy Research Institute (SERI) wind machine airfoil family, are constant chord and not twisted. Initial computer simulations indicated that this blade set had its best power coefficient at a tip-speed ratio of about 7 with the blade pitch set to 3 degrees. As the Combined Experiment tests

\footnotetext{
1 This paper is declared a work of the U.S. Government

and is not subject to copyright protection in the United States.
} 
of these blades had been concluded, they were transferred to the second, or variable-speed, Grumman machine.

The Electric Generator -- By being a successful bidder in the National Renewable Energy Laboratory University Participation Program for Wind Energy, the University of Colorado Electrical and Computer Engineering Department has a contract to custom-design an electric generator. This prototype generator is unconventional for wind energy in two ways. First, it is direct drive, which means it must achieve its full power output at relatively low speeds. Second, it is excited by permanent magnets. This specially designed generator rotor accommodates twelve neodymium iron boron magnets in the form of strips that are parallel to the rotation axis and that lie on the surface of the generator rotor.

This machine is a three-phase, $20 \mathrm{~kW}$ generator with a short-term overload capacity of $30 \mathrm{~kW}$. The work of designing a special core stack for this machine was avoided by using the core of a conventional 150 horsepower induction machine. The generator voltage and frequency are directly proportional to generator speed. In the speed range from 0 to 120 revolutions per minute (RPM) the electric frequency varies continuously from zero to 12 hertz. At the same time the line to line voltage varies from 0 to 600 volts RMS. The normal operating range has been defined to be from 60 to 120 RPM, which implies 6 to $12 \mathrm{~Hz}$ and 300 to $600 \mathrm{~V}$.

The installation of this direct-drive generator required the removal of the induction generator from the second Windstream 33, together with its speed-increasing drive. The new generator is equipped with a hollow drive shaft through which the linkage to the pitch mechanism can pass. Between the outboard generator bearing and the wind machine rotor is mounted the 85 centimeter $(\mathrm{cm})$ disk for the rotor brake. Two electrically driven calipers are positioned to provide the braking torque.

Electrical Load - The final drive train system incorporates custom power electronics to transform the "wild" alternating current to direct current and then back to utility-grade alternating current. The second part of the university contract was to provide appropriate power electronics custom built for the subject generator. However, in order to start testing variable-speed operation of the wind machine prior to its arrival, a primitive resistive load was fabricated. This adjustable load bank is switched using contactors. These contactors are in turn controlled by smaller solid-state relays at the control computer.

The three-phase load bank is formed from eight separate banks of delta-connected resistors, each with its own contactor to connect it to the generator bus. The resistance values of each bank were chosen such that at constant generator voltage, the next larger bank would sink double the current (and power) of the previous bank. With this binary relation, 256 possible balanced, threephase loads equally spaced in power can be applied to the generator.

Wind Machine Control - A personal computer with a Pentium CPU and analog and digital input and output serves as the wind machine controller. Its primary output are the eight binary signals that close or release the loadbank contactors. Another pair of binary outputs drive the pitch motor in either of its two directions.

The software is written in the C Language with appropriate drivers to access the input/output interface. With the resident compiler on the control computer and a skilled operator it is possible to modify control algorithms in one or two minutes during a pause in data collection. The algorithms being tested are discussed below.

An important component in the control system is a primitive computer that operates on a definite and rigid schedule completely independently of the primary control computer. Its sole function is to receive pulses from the primary control computer. If this pulse train is interrupted this small computer assumes primary control has been lost. It immediately takes control of the wind turbine and pitches the blades to feather and sets both rotor and yaw brakes.

\section{Data Collection System}

The ADAS System - The Advanced Data Collection System (ADAS) is an interconnected system of special modules under the control of a personal computer using custom ADAS software. The design philosophy for this system was to create a standard electronic digital data collection box called an Advanced Data Acquisition Module (ADAM). Several of these could be controlled by a single data collection personal computer. The NWTC variable speed installation uses a separate Pentium-equipped personal computer that oversees four ADAM units. These ADAMs simultaneously read up to eight analogue or binary data channels each, and record 
values in their local memory in binary format. When these local memories are filled, they must be emptied into the controlling-master computer hard drive. Although these files are still in binary format, they can be transported to another machine if desired.

Part of the ADAS software is a module that can be installed on any personal computer and is a routine for transforming the raw binary files into data tables with engineering units. This transformation requires a table of calibration constants that is generated during the initial transducer calibration at the test site. This conversion is therefore done either off line using the data collection computer or on the computer in a test engineer's office.

Variables Being Collected The four ADAM units, each with an eight-channel capacity, are assigned the following tasks. In general, unit 2 collects slowly changing quantities-primarily generator temperatures and barometric pressure at six samples per minute. Unit 3 collects electrical quantities at 10 times per second. Unit 4 collects performance variables at 10 samples per second. These three boxes are located in the site shed. The remaining ADAM, Unit 1, is mounted on the rotor hub and records rotor data. The accompanying table provides the details.

\section{Data Collection Format}

In order to collect variable-speed data and also have constant-speed data to serve as a baseline for comparison, we chose to alternate control algorithms. That is, we standardized on collecting 10 minutes of machine operation using variable-speed control followed by 10 minutes of operation with control set to hold a constant speed. Constant-speed set points in multiples of 10 from 60 to 120 RPM are available. All control algorithms are available including idle (high pitch with slow rotation) and are at all times available with one key stroke on the control computer.

\section{Control Algorithms Used}

The Constant-Speed Control Algorithms These algorithms consisted merely of proportional feedback

\begin{tabular}{|l||l|l|l|l|}
\hline Channel. & Unit \#1 (Rotor)* & Unit \# 2 & Unit \# 3 & Unit \# 4 \\
\hline $\begin{array}{c}\text { Sample } \\
\text { Rate }\end{array}$ & \multicolumn{1}{|c|}{$40 / \mathrm{sec}$} & \multicolumn{1}{|c|}{1 /sec } & \multicolumn{1}{|c|}{$10 / \mathrm{sec}$} \\
\hline 1 & Blade 1 flap & Phase A temp. & Phase A voltage & Rotor RPM \\
\hline 2 & Blade 2 flap & Phase B temp. & Phase B voltage & Rotor position \\
\hline 3 & Blade 3 flap & Phase C temp. & Phase C voltage & Generator torque \\
\hline 4 & Blade 1 edge & Gen Case temp. & Phase A current & Wind @ hub - m/s \\
\hline 5 & Blade 2 edge & Nacelle temp. & Phase B current & Wind direction \\
\hline 6 & Blade 3 edge & Atmos. temp. & Phase C current & Yaw position \\
\hline 7 & Angle of attack & (future) & DC bus voltage & (future) \\
\hline 8 & Blade pitch & Barometer $-(\mathrm{mb})$ & DC bus current & Generator power \\
\hline
\end{tabular}

* Channels 1,2, and 3 are downwind root-bending loads in Newton-meters.

Channels 4,5 , and 6 are chordwise or in-plane bending loads in Newton-meters 
using successive set points of $60,70, \ldots, 120$ RPM. Figure 3 shows a coarse overview of an hour's record composed of 10- second averages of wind and rotor speeds. Note the three variable-speed periods in which the rotor speed tends to follow the wind, interleaved with three constant-speed periods of about 60,70 , and 80 RPM each.

The Variable Speed Control Algorithms The variable speed algorithms were created using the following definitions:

Region 2 The wind machine is in operation above the cut-in speed, but below its maximum or rated power. In this region maximum energy capture is the desired behavior.

Region 3 The wind machine is in operation at or slightly above it maximum or rated power. In this region, safety, fatigue life, and retention of control are the primary objectives. (The region boundary is defined as 100 RPM.)

\section{Control in Region 2:}

A. Blade pitch is maintained at 3 degrees by the pitch control loop.

B. Generator torque control. The system uses measured rotor speed entered into a polynomial read out expected generator output power for the maximum power coefficient. The system then selects the appropriate load bank resistor combination to draw that power at that rotor speed. Although the system executes this loop about 70 times per second, the load bank is only updated every half second. Qualitatively, note that if the wind is providing more than the requested power, the rotor will accelerate and the next load bank update will request more power. Similarly, on a declining wind the load bank will progressively decrease the requested power. Operation is quite stable.

\section{Control in Region 3:}

A. Blade pitch is continuously adjusted to maintain the rotor speed constant at 105 RPM.

Two Alternative Options for generator torque are available in this region:

B1. The generator is loaded to a constant torque corresponding to rated power.

B2. The generator is loaded to provide constant rated power.

\section{Some Preliminary Results}

The variable-speed test bed became fully operational at the end of the NWTC high wind season. Although several hours of reliable data had been archived by the time of this writing, there is still not enough data for each of the various algorithms to be statistically significant. Nevertheless, some quite interesting results can be found in the data captured so far.

With data being recorded at one-tenth second intervals, it is not surprising that we found a great deal of scatter in the data points. Some points were recorded when the wind was relatively steady and the machine was in dynamic equilibrium with it. At other times the wind would suddenly lull from a relatively high value. If one calculates the instantaneous power coefficient at this time, the instantaneous power from the spinning rotor is paired with a small wind speed so that the calculated power coefficient is unrealistically high-often over 1.5. Correspondingly low coefficients can likewise be calculated.

A mass of merged instantaneous data is shown in Figure 4. The wind, RPM, and torque from one month's data were merged into one table. All constant-speed data were kept separate from the variable-speed data. Instantaneous power and power coefficient were also calculated. The power coefficients for the two modes of operation were then binned into wind bins of one-quarter meter per second width. The constant-speed curve conforms closely to its expected shape. The measured variable-speed data points, though scattered, show a tendency to constancy for wind speeds up to about 7 meters per second. The data matrix shows that wind speed drives the rotor to 100 RPM, which is the transition to Region 3. The measured points for higher winds show the expected drop-off for a constant-speed machine. 


\section{Future Plans and Conclusions}

Obviously, before statistically valid assertions can be made, an order of magnitude more constant and variablespeed data must be recorded. The NWTC is now building that data set and simultaneously is reducing and analyzing it.

The initial thrust of the data analysis has been directed toward understanding the flow of energy from the wind to the wind machine rotor hub. The other-and perhaps more important-half of the variable speed effort is to understand the effect of variable-speed on wind machine loads and fatigue. Initial examination of that store of data is under way. Finally, the measurements collected from the recently added power electronics will be examined.

\section{Acknowledgment}

The U.S. Department of Energy is credited for its funding of this document through the National Renewable Energy Laboratory under contract number DE-AC36$83 \mathrm{CH} 10093$.

\section{Bibliography}

American Wind Energy Association, Standard Perfomnace Testing of Wind energy Conversion Systems,AWEA Standard AWEA $1.1-1988$.

Proceedings of Windpower '93, San Francisco, CA, July 1993, American Wind Energy Association, "A Variablespeed, Direct-drive Transmission Wind Power Plant," pp $134-141$.

Lee Jay Fingersh, The Testing of a Low-Speed, Permanent magnet Generator for Wind Poer applications", Master's Thesis, University of Colorado, Department of Electrical Engineering, 1995.

Adavanced Data Acquistion Systems Manual, Zond Systems, Inc., 13000 Jameson Road, Tehachapi, CA

Brian W. Gregory, Current Control of an Inverter via Computer-Controlled Arbitrarv Function Generator", Master's Thesis, University of Colorado Electrical
Engineering Department, 1993.

American Wind Energy Association, Standard Performance Testing of Wind Energy Conversion Systems, AWEA Standard AWEA 1.1 - 1988. 


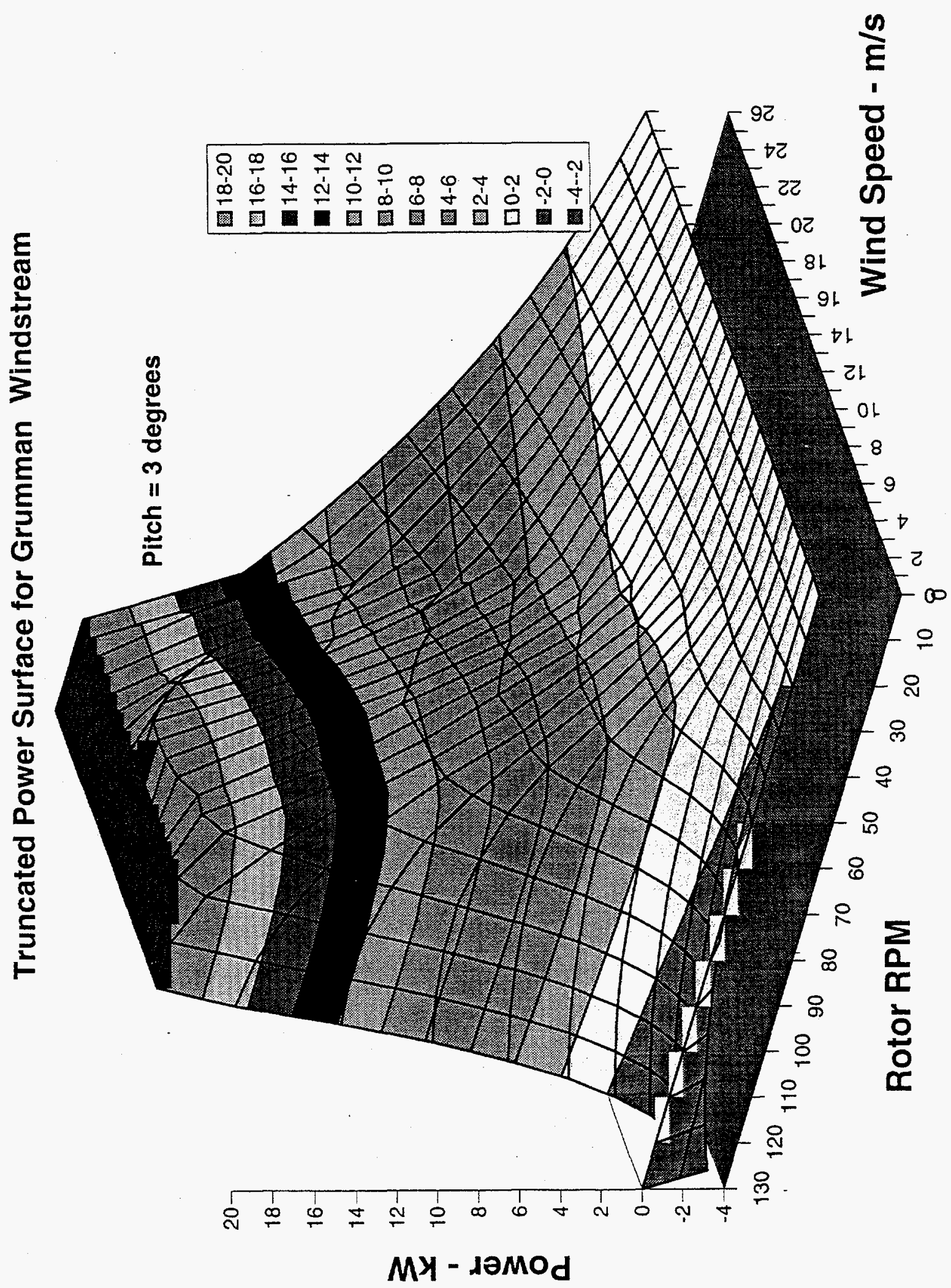

Figure 1 


\section{z วมกริ!}

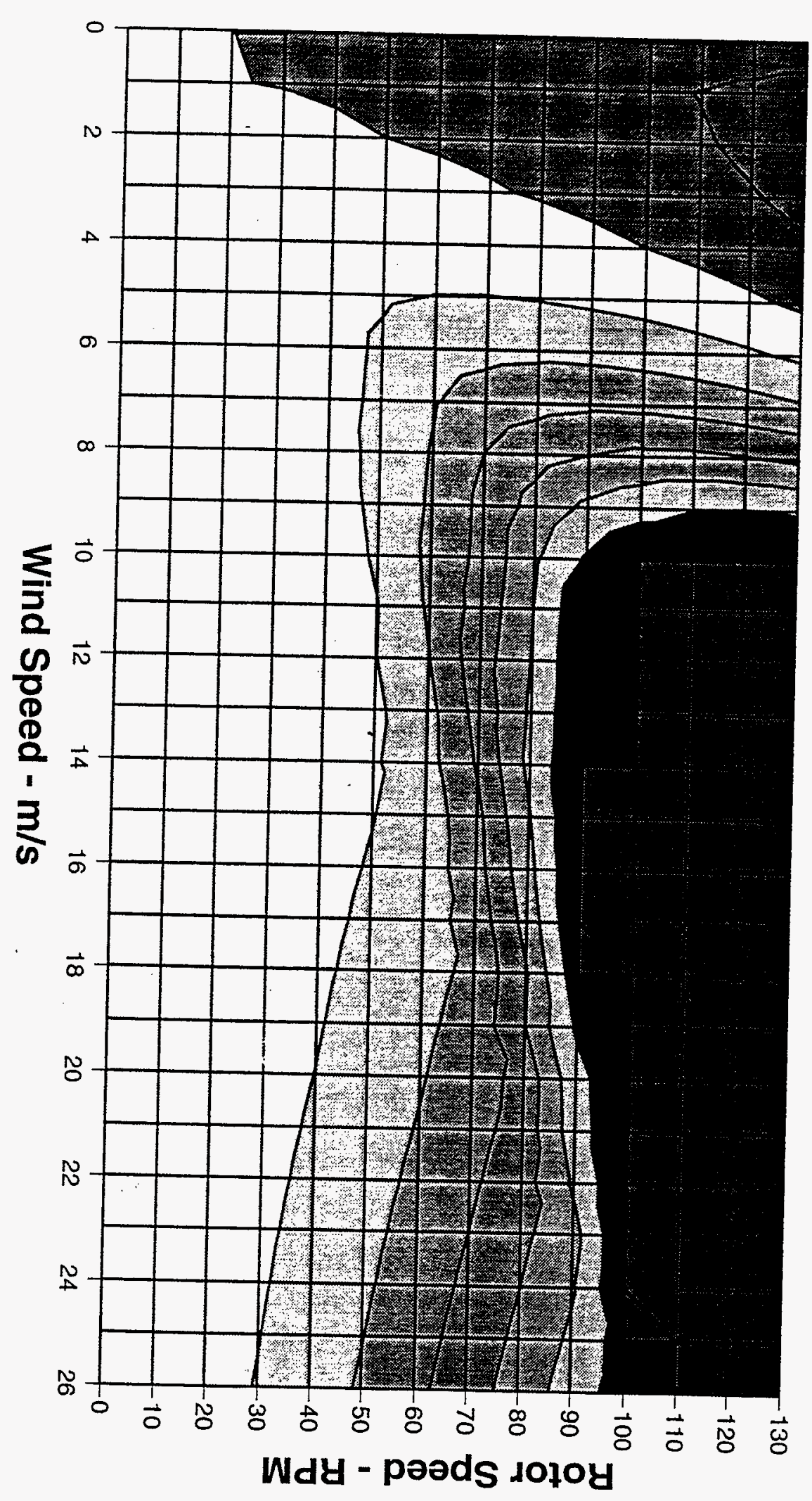




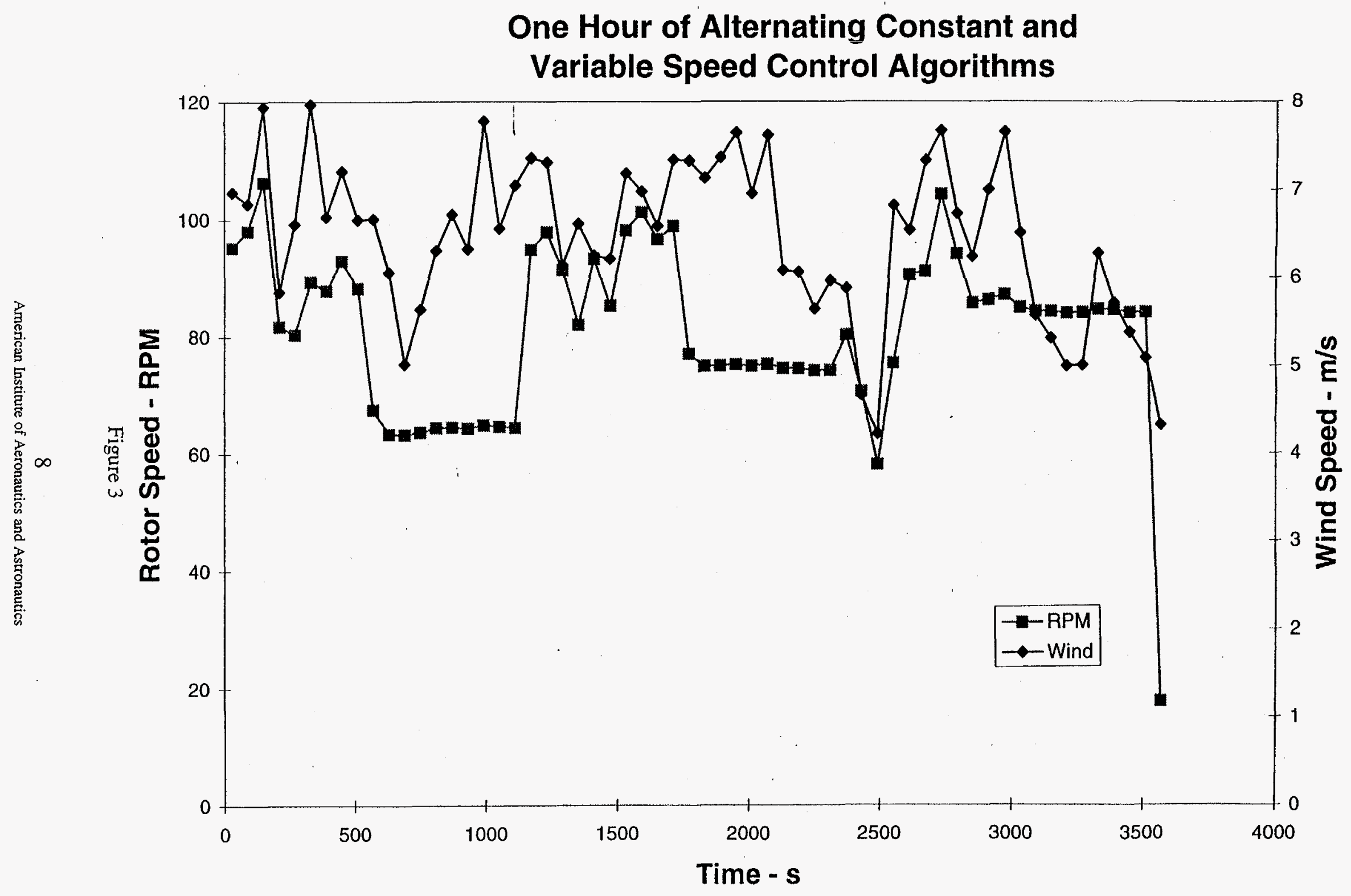




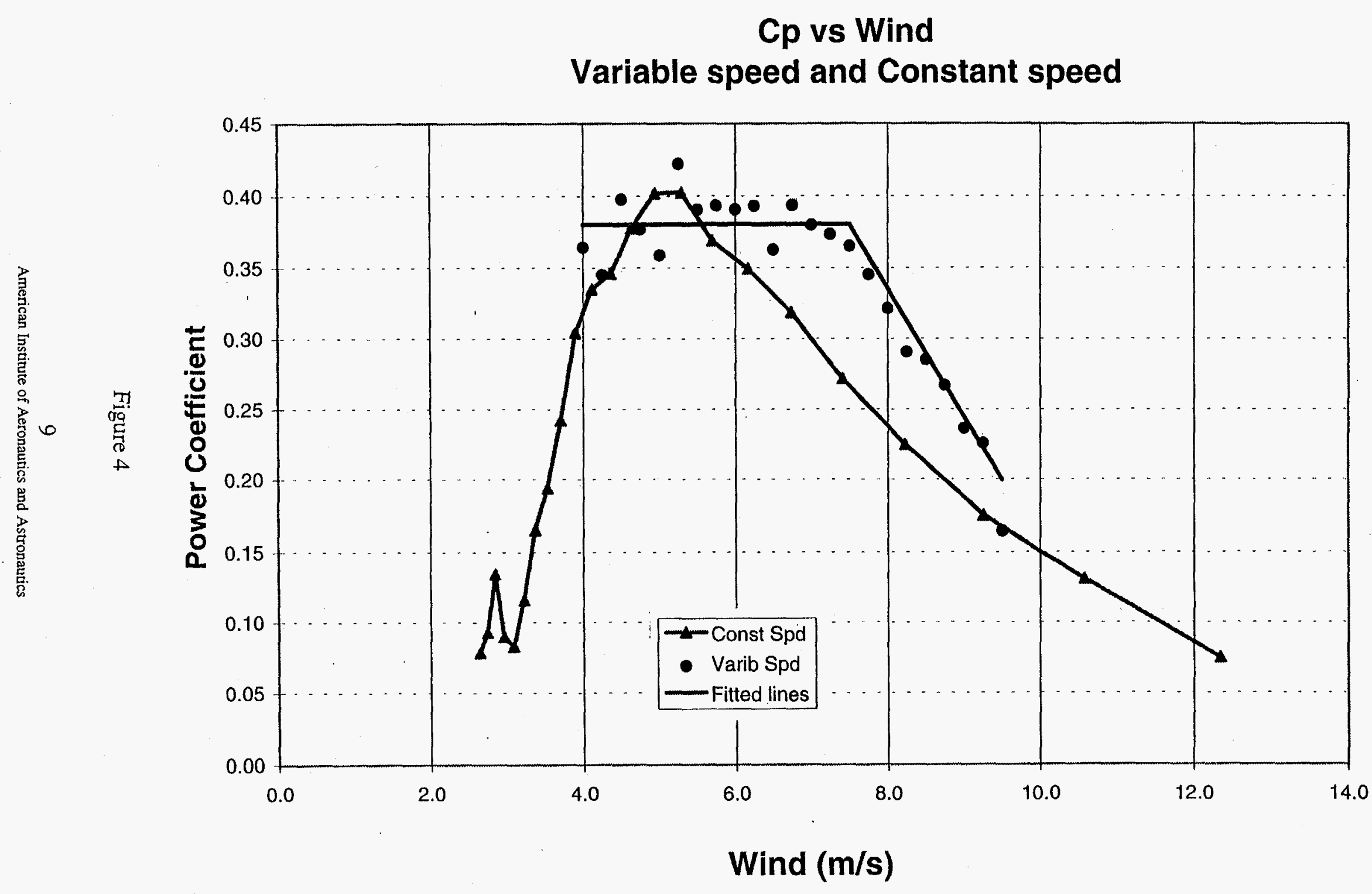

